\title{
Naloxone for administration by peers in cases of heroin overdose
}

\author{
Simon R Lenton, Paul M Dietze, Louisa Degenhardt, Shane Darke, Tony G Butler
}

TO THE EDITOR: We wish to call for the removal of scheduling and legislative barriers in Australia that prevent easy access to naloxone for administration by peers to people suffering from a heroin overdose.

Use of illicit opioids, typically heroin, remains the major cause of illicit drug-related mortality in this country, with at least one accidental opioid overdose currently occurring each day. ${ }^{1,}$ Although population levels have not reached those seen during the peak in the late 1990s, geographically localised and transient increases in overdoses are evident ${ }^{2}$

Mortality from heroin overdose typically occurs some time after use. In many cases, other people are present, and there is considerable scope for intervention to prevent death. ${ }^{3}$ Yet, in more than $70 \%$ of cases of fatal overdose, there is no intervention, and, where action is taken, calling an ambulance is seldom the first strategy, resulting in even greater risk of mortality. ${ }^{3}$

Opioid substitution treatment (with methadone or buprenorphine) is the mainstay of overdose prevention in Australia. Other interventions implemented here include outreach services and education for injecting drug users about the risks of overdose and how to respond to it. ${ }^{3}$

In 2000, Lenton and Hargreaves summarised the evidence for distributing the opioid antagonist naloxone for administration by peers to prevent deaths from heroin overdose. They concluded that an Australian research trial was needed. ${ }^{4}$ When, in 2001, the Australian heroin market was disrupted and heroin use and overdoses declined, the trial did not proceed.

Since then, emerging international evidence has demonstrated that injecting drug-using peers, family members and outreach workers can successfully administer naloxone to reverse heroin overdose - with few, if any, adverse effects. ${ }^{5}$ By December 2008 in the United States, 52 programs distributing naloxone for administration by peers were operating in 17 states, with over 1000 documented overdose reversals resulting from these programs. ${ }^{5}$ Most concerns about the intervention - such as the possibility of unsafe naloxone administration, reintoxication or more risky drug use - appear to have been unfounded, and naloxone administration by trained peers has been shown to be a remarkably safe intervention. ${ }^{5}$

In our view, the international evidence clearly indicates that increased naloxone availability will prevent many cases of fatal overdose, that conducting a trial in Australia is now unnecessary, and that naloxone should be made available without delay to be administered by peers in cases of opioid overdose. Careful monitoring and evaluation should be a part of this process.

We call on all Australian states and territories to immediately enact Good Samaritan legislation to legally protect lay people using naloxone in emergency situations. Naloxone should be reclassified from a Schedule 4 (S4) drug (available only on prescription) to S3 or S2 to make it available over the counter. As naloxone is no longer under patent, ${ }^{5}$ there may be little financial incentive for a drug company to pursue rescheduling. However, it could be rescheduled in Australia under provisions that allow state health authorities, professional associations or the National Drugs and Poisons Schedule Committee to initiate the process.

Heroin overdose deaths are preventable. We need to take action now to enable this peer-led intervention to reduce this serious outcome.

Competing interests: Louisa Degenhardt has received an untied educational grant from Reckitt Benckiser to investigate the diversion and injection of buprenorphine. No funder had any input to this letter.

Simon R Lenton Professor and Deputy Director ${ }^{1}$

Paul M Dietze Principal Research Fellow and Associate Professor ${ }^{2}$

Louisa Degenhardt Professor and Assistant Director ${ }^{3}$

Shane Darke Professor ${ }^{3}$

Tony G Butler Associate Professor ${ }^{1}$

1 National Drug Research Institute, Curtin University of Technology, Perth, WA.

2 Burnet Institute, Monash Institute of Health Services Research, Monash University, Melbourne, Vic.

3 National Drug and Alcohol Research Centre, University of New South Wales, Sydney, NSW.

s.lenton@curtin.edu.au

1 Black E, Roxburgh A, Degenhardt L, et al. Australian drug trends 2007: findings from the Illicit Drug Reporting System (IDRS). Sydney: National Drug and Alcohol Research Centre, 2008.

2 Cvetkovski S, McElwee P. Surveillance of drug related events attended by ambulance in Melbourne. Quarterly report no. 19. Melbourne: Turning Point Alcohol and Drug Centre, 2009.

3 Darke S, Hall W. Heroin overdose: research and evidence-based intervention. J Urban Health 2003; 80: $189-200$.

4 Lenton SR, Hargreaves KM. Should we conduct a trial of distributing naloxone to heroin users for peer administration to $\begin{array}{llllll}\text { prevent fatal } & \text { overdose? } & \text { Aust } & \text { 2000; } & \text { 173: } 260-263 .\end{array}$ http://www.mja.com.au/public/issues/173 05 040900/lenton/lenton.html

$5 \mathrm{Kim}$ D, Irwin KS, Khoshnood K. Expanded access to naloxone: options for critical response to the epidemic of opioid overdose mortality. Am J Public Health 2009; 99: 402-407. 